\title{
Modeled and observed properties related to the direct aerosol radiative effect of biomass burning aerosol over the Southeast Atlantic
}

Sarah J. Doherty ${ }^{1,2}$, Pablo E. Saide ${ }^{3,4}$, Paquita Zuidema ${ }^{5}$, Yohei Shinozuka ${ }^{6,7}$, Gonzalo A. Ferrada ${ }^{8}$, Hamish Gordon ${ }^{9}$, Marc

5 Mallet $^{10}$, Kerry Meyer ${ }^{11}$, David Painemal ${ }^{12,13}$, Steven G. Howell ${ }^{14}$, Steffen Freitag ${ }^{14}$, Amie Dobracki ${ }^{5}$, James R. Podolske ${ }^{7}$, Sharon P. Burton ${ }^{13}$, Richard A. Ferrare ${ }^{13}$, Calvin Howes ${ }^{3}$, Pierre Nabat ${ }^{10}$, Gregory R. Carmichael ${ }^{8}$, Arlindo da Silva ${ }^{15}$, Kristina Pistone ${ }^{6,7}$, Ian Chang ${ }^{16}$, Lan Gao ${ }^{16}$, Robert Wood ${ }^{2}$ and Jens Redemann ${ }^{16}$

${ }^{1}$ Cooperative Institute for Climate, Ocean and Ecosystem Studies, Seattle, WA, USA

$10{ }^{2}$ Department of Atmospheric Science, University of Washington, Seattle, WA, USA

${ }^{3}$ Department of Atmospheric and Oceanic Sciences, University of California, Los Angeles, CA USA

${ }^{4}$ Institute of the Environment and Sustainability, University of California, Los Angeles, CA, USA

${ }^{5}$ Rosenstiel School of Marine and Atmospheric Science, University of Miami, Miami, FL, USA

${ }^{6}$ Bay Area Environmental Research Institute, Moffett Field, CA, USA

$15{ }^{7}$ NASA Ames Research Center, Moffett Field, CA, USA

${ }^{8}$ Center for Global and Regional Environmental Research, The University of Iowa, Iowa City, IA, USA

${ }_{9}^{9}$ Engineering Research Accelerator and Center for Atmospheric Particle Studies, Carnegie Mellon University, Pittsburgh, PA, USA

${ }^{10}$ CNRM, Université de Toulouse, Météo-France, CNRS, Toulouse, France

$20{ }^{11}$ NASA Goddard Space Flight Center, Greenbelt, Maryland, MD 20771, USA

${ }^{12}$ Science Systems and Applications Inc., Hampton, Virginia 23666, USA

${ }^{13}$ NASA Langley Research Center, Hampton, Virginia 23691 USA

${ }^{14}$ University of Hawaii at Manoa, Honolulu, HI, USA

${ }^{15}$ Global Modeling and Assimilation Office, NASA Goddard Space Flight Center, Greenbelt, MD, USA

$25{ }^{16}$ School of Meteorology, University of Oklahoma, Norman, OK, USA

Correspondence to: Sarah J. Doherty (sarahd@atmos.washington.edu)

\section{SUPPLEMENTAL INFORMATION}


35 Table S1. Coordinates of the four transects of gridboxes used in this comparison. Gridboxes are numbered 1-8 (Diagonal, Meridional) or 1-11 (Zonal) from west to east and/or north to south.

\begin{tabular}{|c|c|c|c|}
\hline Transect Name & Year(s) & Latitude & Longitude \\
\hline Diagonal $^{+}$ & 2016 & $\begin{array}{l}7-11 S \\
9-13 S \\
11-15 S \\
13-17 S \\
15-19 S \\
17-21 S \\
19-23 S \\
21-25 S\end{array}$ & $\begin{array}{l}\mathrm{W}-2 \mathrm{E} \\
0-4 \mathrm{E} \\
2-6 \mathrm{E} \\
4-8 \mathrm{E} \\
6-10 \mathrm{E} \\
8-12 \mathrm{E} \\
10-14 \mathrm{E} \\
12-16 \mathrm{E}\end{array}$ \\
\hline Meridional1 & 2016 & $\begin{array}{l}7-9 \mathrm{~S} \\
9-11 \mathrm{~S} \\
11-13 \mathrm{~S} \\
13-15 \mathrm{~S} \\
15-17 \mathrm{~S} \\
17-19 \mathrm{~S} \\
19-21 \mathrm{~S} \\
21-23 \mathrm{~S}\end{array}$ & $9-11.75 \mathrm{E}$ \\
\hline Zonal & 2016,2017 & $6-10 \mathrm{~S}$ & $\begin{array}{l}15-13 \mathrm{~W} \\
13-11 \mathrm{~W} \\
11-9 \mathrm{~W} \\
9-7 \mathrm{~W} \\
7-5 \mathrm{~W} \\
5-3 \mathrm{~W} \\
3-1 \mathrm{~W} \\
1 \mathrm{~W}-1 \mathrm{E} \\
1-3 \mathrm{E} \\
3-5 \mathrm{E} \\
5-7 \mathrm{E}\end{array}$ \\
\hline Meridional2 & 2017,2018 & $\begin{array}{l}0.5 \mathrm{~N}-1.5 \mathrm{~S} \\
1.5-3.5 \mathrm{~S} \\
3.5-5.5 \mathrm{~S} \\
5.5-7.5 \mathrm{~S} \\
7.5-9.5 \mathrm{~S} \\
9.5-11.5 \mathrm{~S} \\
11.5-13.5 \mathrm{~S} \\
13.5-15.5 \mathrm{~S}\end{array}$ & $4-6 \mathrm{E}$ \\
\hline
\end{tabular}

'For the Diagonal transect, coordinates given are for the latitudes of the north and south corners and the longitudes of the east and west corners of the gridbox. 
Table S.2: The difference between the average of $\mathrm{CF}_{\text {warm }}$ at 10:30 and 13:30 and $\mathrm{CF}_{\text {warm }}$ for all times when $\mathrm{SZA}<75^{\circ}$ (i.e. the expected ratio of MODIS daily avg $\mathrm{CF}_{\text {warm }}$ vs SEVIRI daily avg $\mathrm{CF}_{\text {warm }}$ ) during the three field campaign periods

45

\begin{tabular}{|c|c|c|c|}
\hline \multicolumn{5}{|c|}{ a) Zonal Transect } \\
\hline Gridbox & & & \\
\hline 1 & $\mathbf{2 0 1 6}$ & $\mathbf{2 0 1 7}$ & $\mathbf{2 0 1 8}$ \\
\hline 2 & -0.025 & -0.009 & -0.010 \\
\hline 3 & -0.030 & 0.002 & $-0.010 \quad 50$ \\
\hline 4 & -0.034 & 0.007 & -0.006 \\
\hline 5 & -0.024 & -0.021 & -0.008 \\
\hline 6 & -0.013 & -0.027 & -0.008 \\
\hline 7 & -0.023 & -0.016 & -0.003 \\
\hline 8 & -0.024 & -0.018 & 0.004 \\
\hline 9 & -0.023 & -0.018 & 0.001 \\
\hline 10 & -0.030 & -0.013 & -0.015 \\
\hline 11 & -0.038 & -0.020 & -0.014 \\
\hline mean & -0.042 & -0.032 & -0.001 \\
\hline std dev & -0.053 & -0.081 & 0.000 \\
\hline
\end{tabular}

\begin{tabular}{|c|c|}
\hline \multicolumn{2}{|c|}{$\begin{array}{c}\text { b) Diagonal } \\
\text { Transect }\end{array}$} \\
\hline $\begin{array}{c}\text { Gridbox } \\
\text { (NW->SE) }\end{array}$ & $\mathbf{2 0 1 6}$ \\
\hline 1 & -0.007 \\
\hline 2 & -0.004 \\
\hline 3 & -0.007 \\
\hline 4 & -0.030 \\
\hline 5 & -0.024 \\
\hline 6 & 0.002 \\
\hline 7 & -0.007 \\
\hline 8 & -0.010 \\
\hline mean & -0.011 \\
\hline std dev & 0.011 \\
\hline
\end{tabular}

\begin{tabular}{|c|c|}
\hline \multicolumn{2}{|c|}{ c) Meridional1 Transect } \\
\hline $\begin{array}{c}\text { Gridbox } \\
\text { (N->S) }\end{array}$ & $\mathbf{2 0 1 6}$ \\
\hline 1 & -0.094 \\
\hline 2 & -0.143 \\
\hline 3 & -0.135 \\
\hline 4 & -0.090 \\
\hline 5 & -0.030 \\
\hline 6 & 0.053 \\
\hline 7 & 0.051 \\
\hline 8 & 0.094 \\
\hline mean & -0.037 \\
\hline std dev & 0.092 \\
\hline
\end{tabular}

\begin{tabular}{|c|c|c|}
\hline \multicolumn{3}{|c|}{ d) Meridional2 } \\
Transect \\
\hline $\begin{array}{c}\text { Gridbox } \\
\text { (N->S) }\end{array}$ & $\mathbf{2 0 1 7}$ & $\mathbf{2 0 1 8}$ \\
\hline 1 & -0.080 & 0.10565 \\
\hline 2 & -0.068 & 0.102 \\
\hline 3 & -0.040 & 0.040 \\
\hline 4 & -0.058 & -0.053 \\
\hline 5 & -0.008 & -0.079 \\
\hline 6 & 0.012 & -0.096 \\
\hline 7 & -0.012 & -0.081 \\
\hline 8 & -0.034 & -0.115 \\
\hline mean & -0.036 & -0.022 \\
\hline std dev & 0.032 & 0.090 \\
\hline
\end{tabular}


Table S.3: As in Table S.2, but showing the difference in median COT warm at 10:30 and 13:30 versus the median for the full daytime, based on an empirical fit to $\mathrm{COT}_{\text {warm }}$ versus $\mathrm{CF}_{\text {warm }}$ from the MODIS-ACAERO retrievals.

\begin{tabular}{|c|c|c|c|}
\hline \multicolumn{5}{|c|}{ a) Zonal Transect } \\
\hline $\begin{array}{c}\text { Gridbox } \\
\text { (W->E) }\end{array}$ & $\mathbf{2 0 1 6}$ & $\mathbf{2 0 1 7}$ & $\mathbf{2 0 1 8}$ \\
\hline 1 & -0.37 & -0.16 & -0.27 \\
\hline 2 & -0.41 & -0.06 & -0.66 \\
\hline 3 & -0.50 & 0.00 & -0.85 \\
\hline 4 & -0.38 & -0.30 & -0.73 \\
\hline 5 & -0.23 & -0.42 & -0.85 \\
\hline 6 & -0.39 & -0.27 & -0.58 \\
\hline 7 & -0.41 & -0.29 & -0.46 \\
\hline 8 & -0.41 & -0.30 & -0.37 \\
\hline 9 & -0.51 & -0.24 & -0.54 \\
\hline 10 & -0.63 & -0.36 & -0.34 \\
\hline 11 & -0.66 & -0.51 & -0.34 \\
\hline mean & -0.78 & -1.05 & -0.06 \\
\hline std dev & -0.88 & -0.97 & -0.38 \\
\hline
\end{tabular}

\begin{tabular}{|c|c|}
\hline \multicolumn{2}{|c|}{$\begin{array}{c}\text { b) Diagonal } \\
\text { Transect }\end{array}$} \\
\hline $\begin{array}{c}\text { Gridbox } \\
\text { (NW->SE) }\end{array}$ & $\mathbf{2 0 1 6}$ \\
\hline 1 & -0.14 \\
\hline 2 & -0.08 \\
\hline 3 & -0.14 \\
\hline 4 & -0.50 \\
\hline 5 & -0.37 \\
\hline 6 & 0.01 \\
\hline 7 & -0.12 \\
\hline 8 & -0.11 \\
\hline mean & -0.18 \\
\hline std dev & 0.17 \\
\hline
\end{tabular}

\begin{tabular}{|c|c|}
\hline \multicolumn{2}{|c|}{ c) Meridional1 Transect } \\
\hline $\begin{array}{c}\text { Gridbox } \\
\text { (N->S) }\end{array}$ & $\mathbf{2 0 1 6}$ \\
\hline 1 & -1.03 \\
\hline 2 & -1.12 \\
\hline 3 & -0.79 \\
\hline 4 & -0.58 \\
\hline 5 & -0.43 \\
\hline 6 & -0.38 \\
\hline 7 & -0.01 \\
\hline 8 & 0.22 \\
\hline mean & -0.52 \\
\hline std dev & 0.47 \\
\hline
\end{tabular}

\begin{tabular}{|c|c|c|}
\hline \multicolumn{3}{|c|}{$\begin{array}{c}\text { d) Meridional2 } \\
\text { Transect }\end{array}$} \\
\hline $\begin{array}{c}\text { Gridbox } \\
\text { (N->S) }\end{array}$ & $\mathbf{2 0 1 7}$ & $\mathbf{2 0 1 8} 8$ \\
\hline 1 & -0.96 & -0.02 \\
\hline 2 & -0.82 & -0.06 \\
\hline 3 & -0.49 & -0.21 \\
\hline 4 & -0.67 & -0.39 \\
\hline 5 & -0.20 & -0.45 \\
\hline 6 & 0.19 & -0.29 \\
\hline 7 & -0.23 & -0.518 \\
\hline 8 & -0.61 & -0.32 \\
\hline mean & -0.48 & -0.28 \\
\hline std dev & 0.38 & 0.18 \\
\hline
\end{tabular}



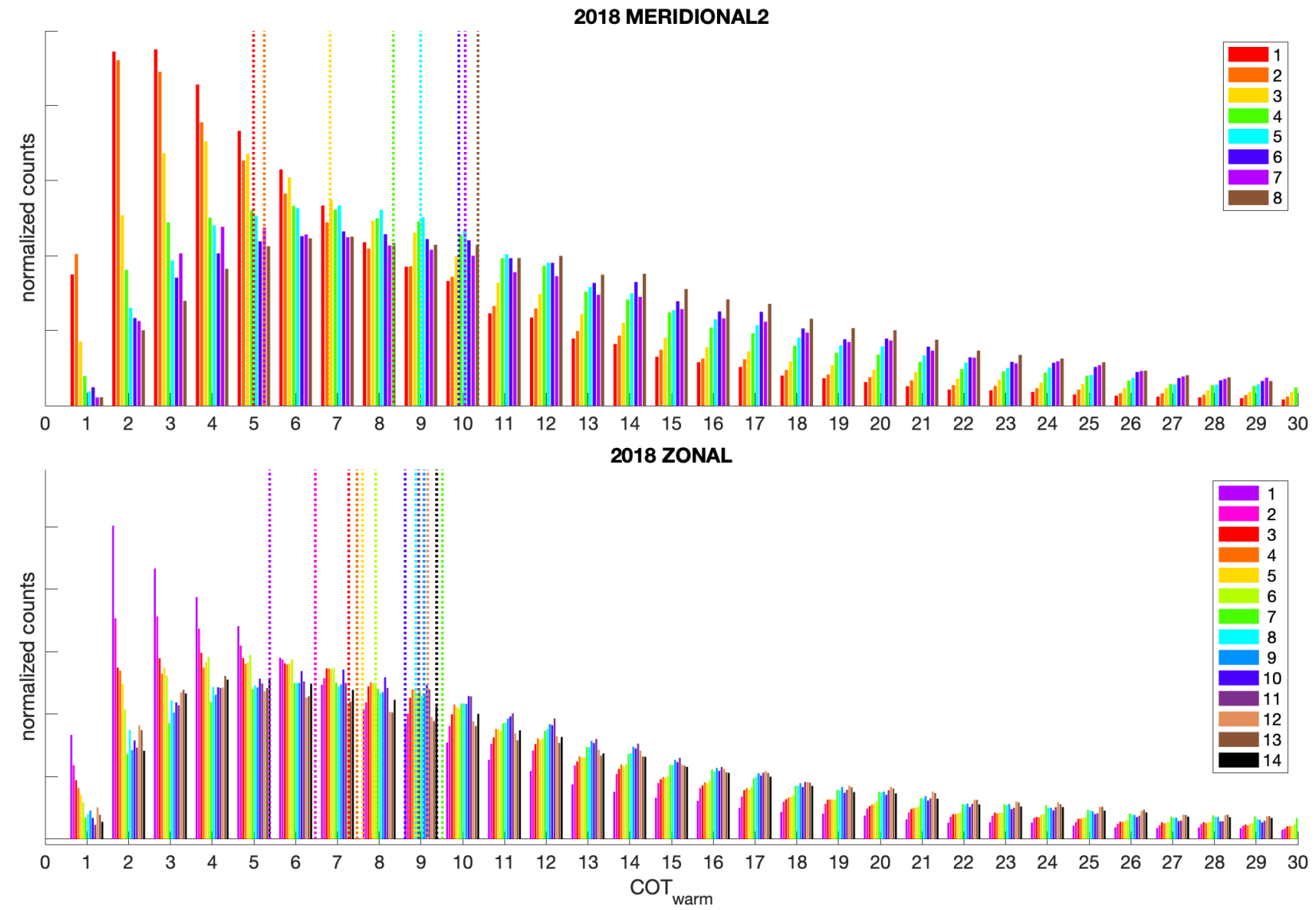

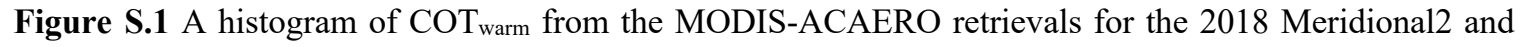
Zonal transects, colored by transect gridbox number (Figure 1). COT warm for the transects in 2016 and 2018 have similarly shaped distributions. 

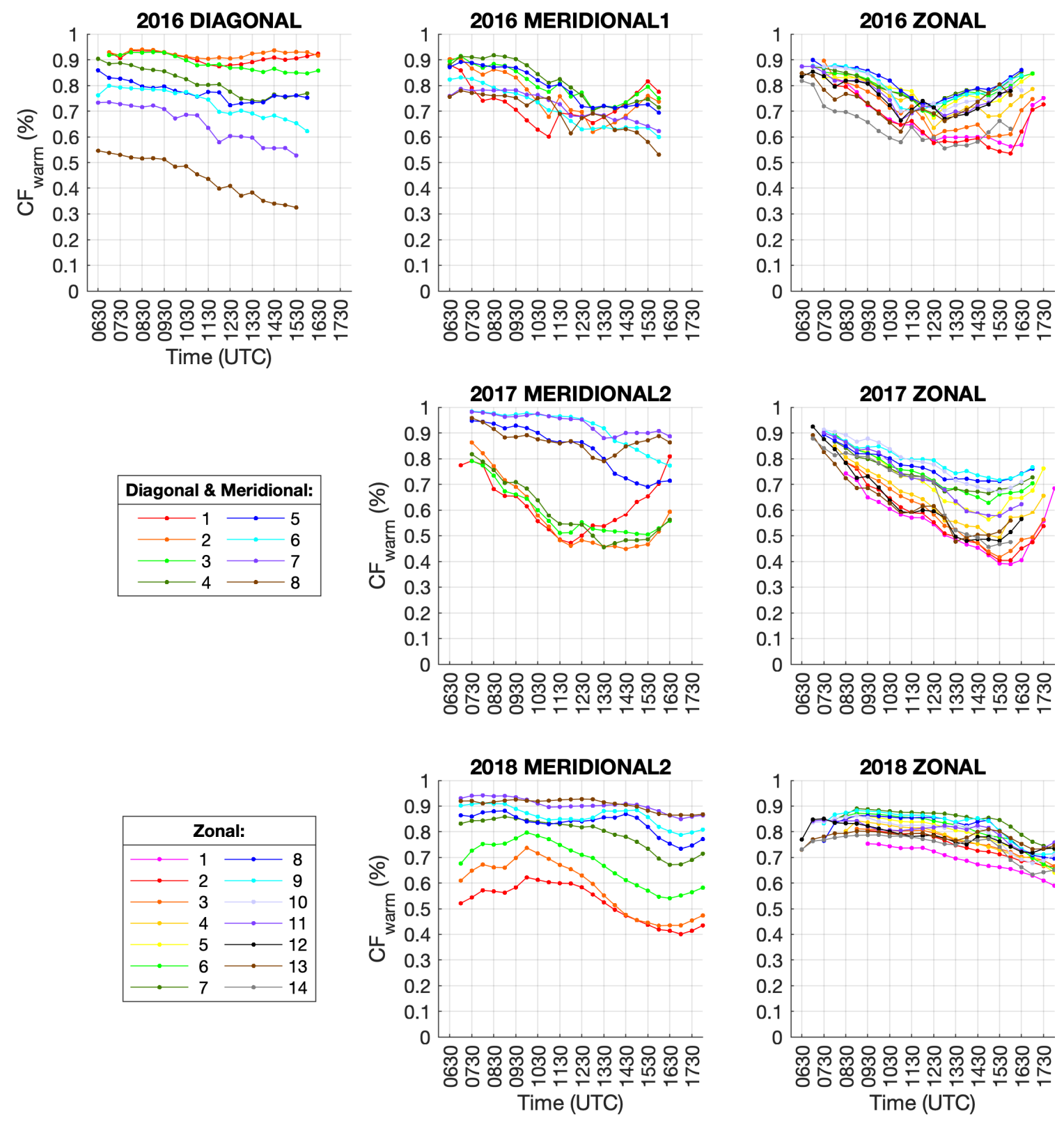

Figure S.2 $\mathrm{CF}_{\text {warm }}$ from the SEVIRI-LaRC retrievals, for all times when $\mathrm{SZA}<75^{\circ}$, showing the diurnal cycle in CF across the comparison gridboxes during the dates of the ORACLES field campaigns in 2016, 2017 and 2018. 

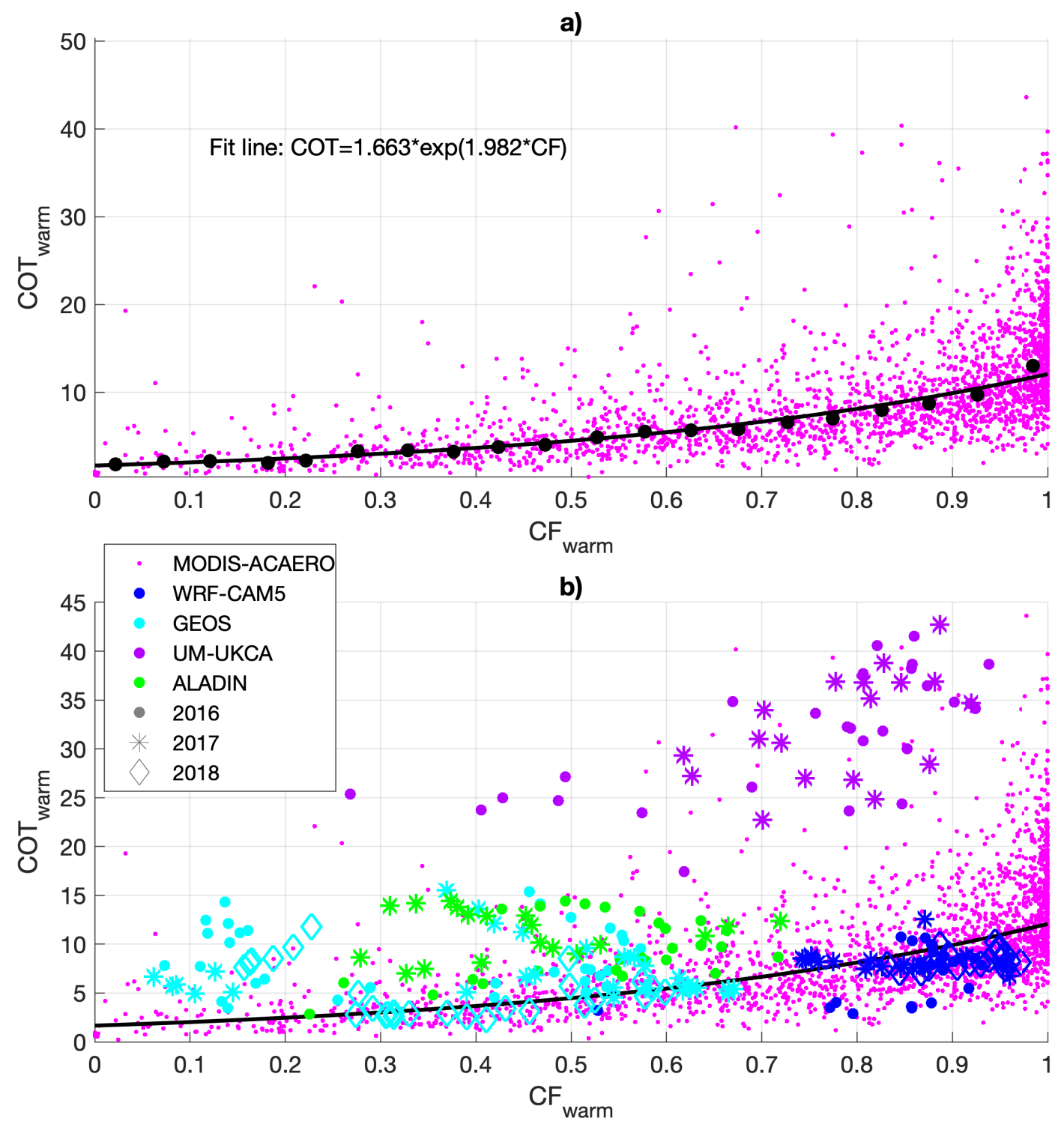

Figure S.3 $\mathrm{COT}_{\text {warm }}$ versus $\mathrm{CF}_{\text {warm }}$ for a) pixel-level MODIS-ACAERO retrievals, with an empirical fit using averages (blue dots) in $\mathrm{CF}_{\text {warm }}$ bins of 0.05 , and b) for both MODIS-ACAERO pixel-level retrievals gridbox averages from the four models included in this comparison. 
a)

115

120

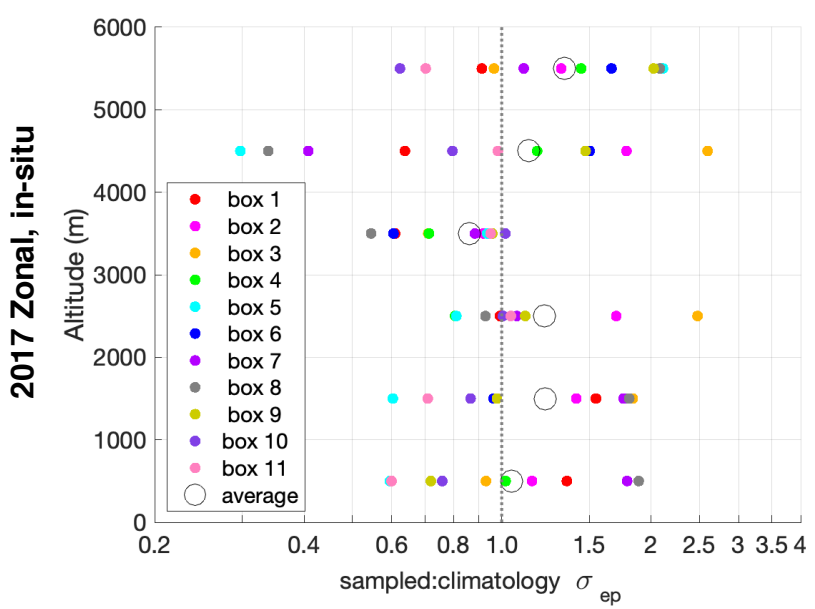

c)

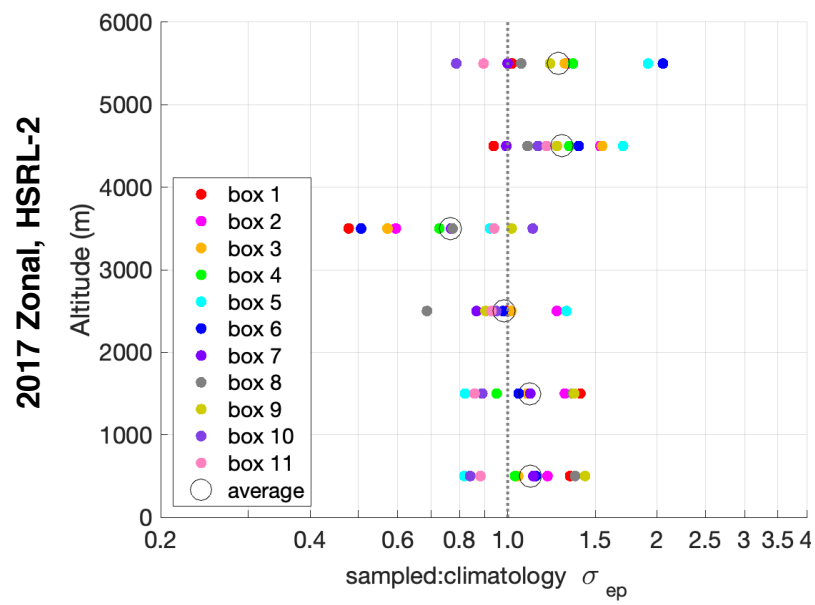

b)

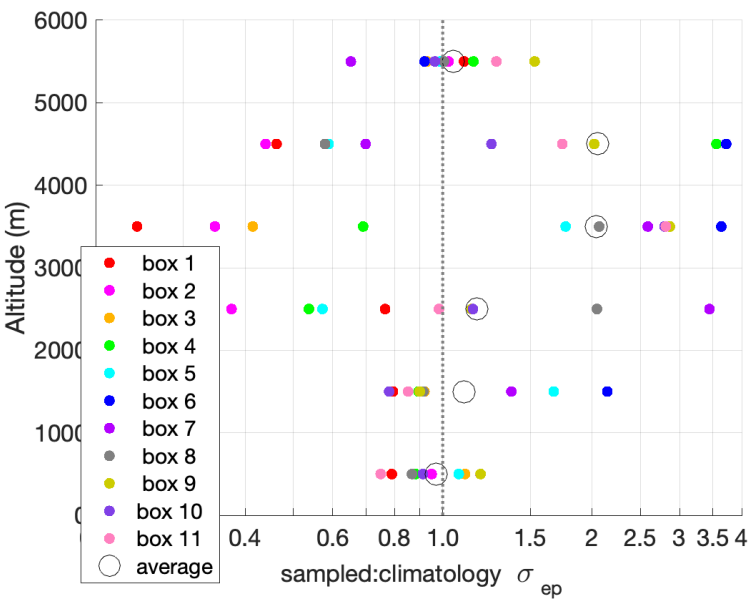

d)

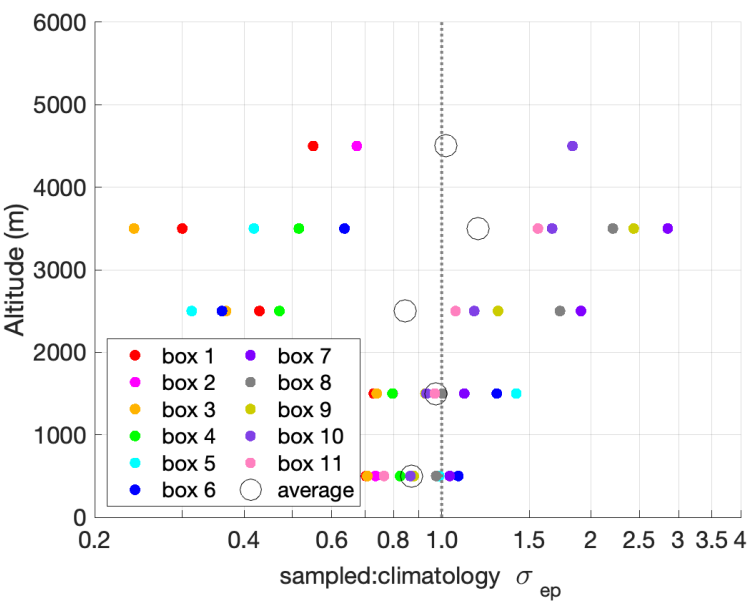

Figure S.4 As in Figure 3: Plots showing the representativeness of the in -situ ( $a$ and b) and HSRL-2 (c and d) sampled values of $\sigma_{\text {ep }}$ for the 2017 Zonal transect from WRF-CAM5 simulations (a and c) and GEOS simulations (b and d). 


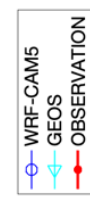

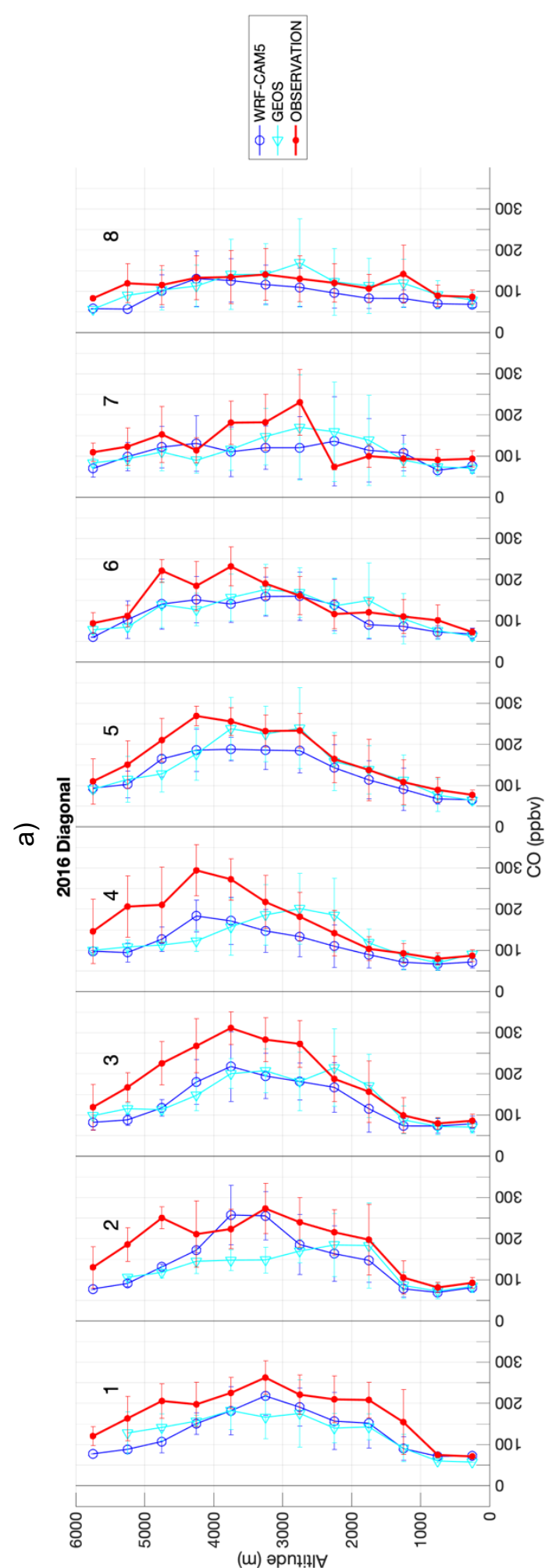

145

150

155

160

165

170

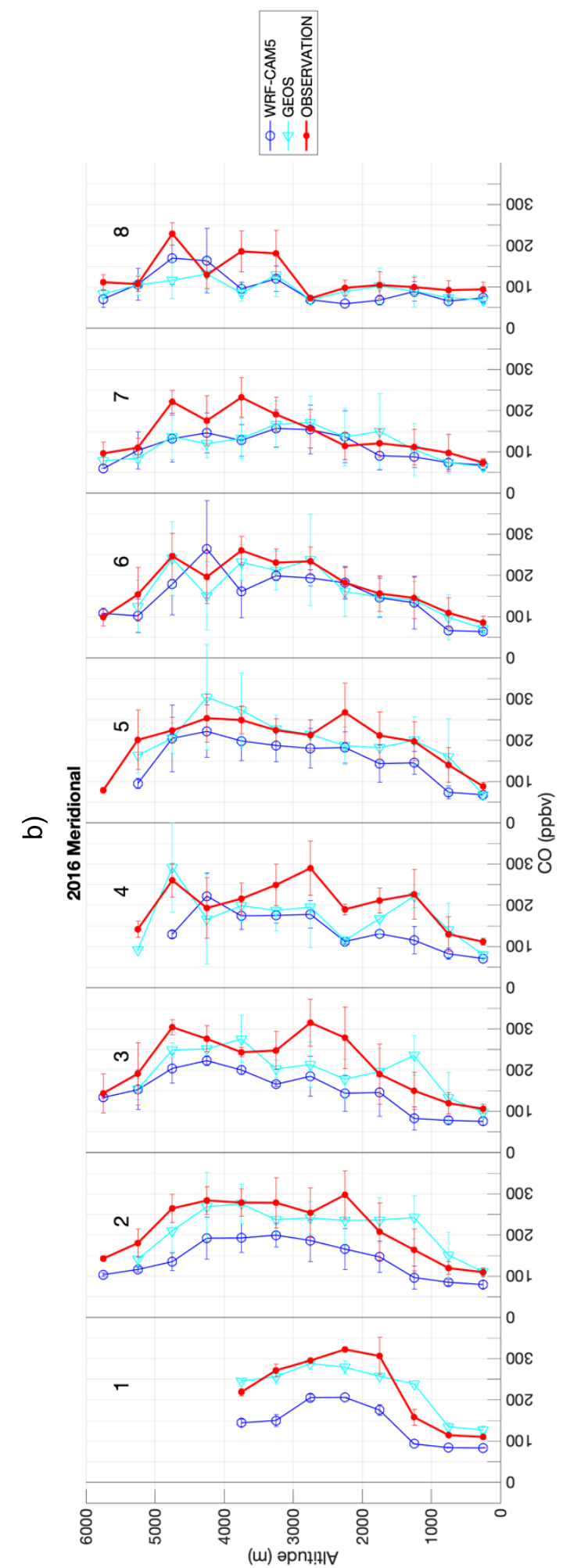


175

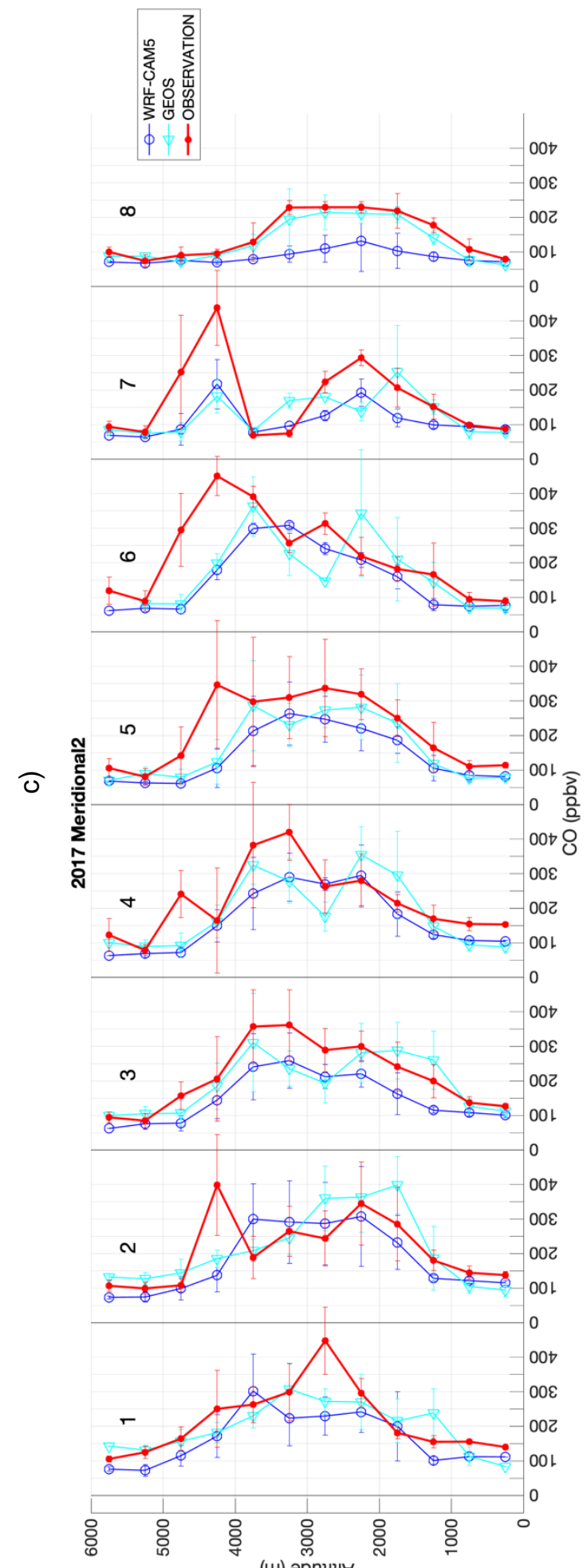

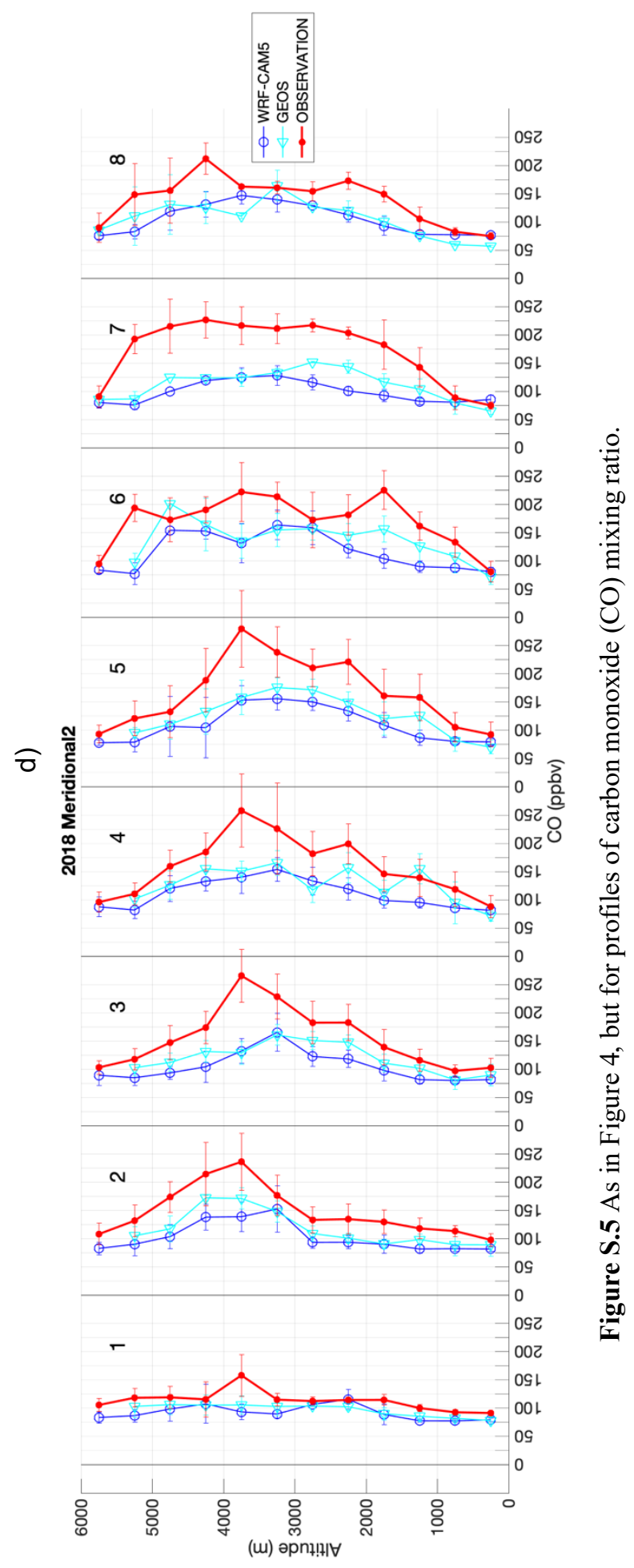




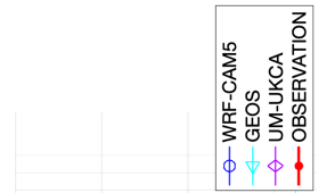

$\infty$
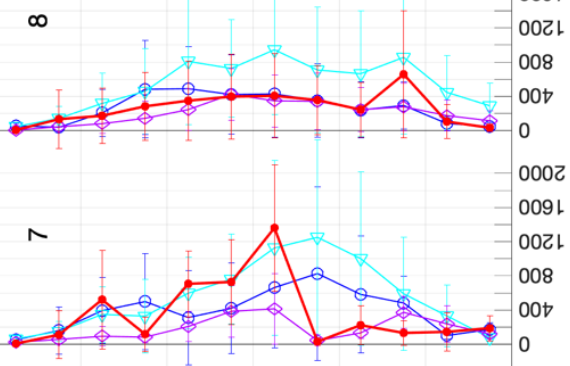

0002

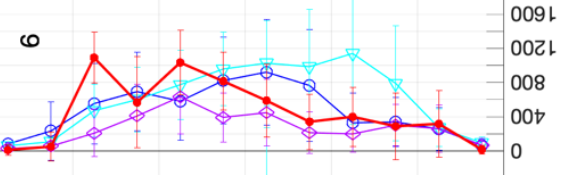

220

225

230

235

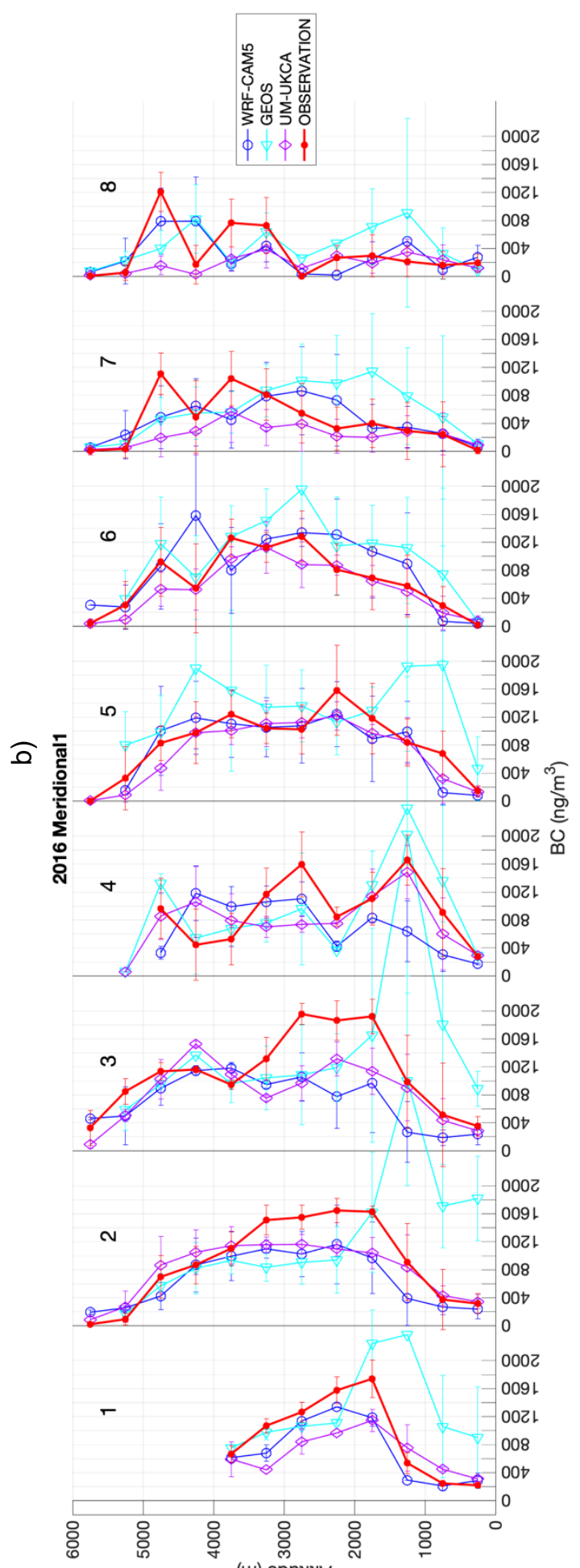

(w) әpn+!+t 


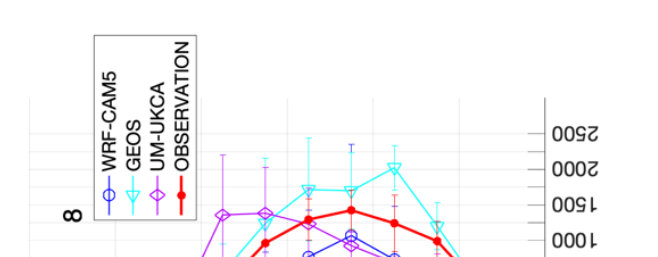

250

255

260

265

270

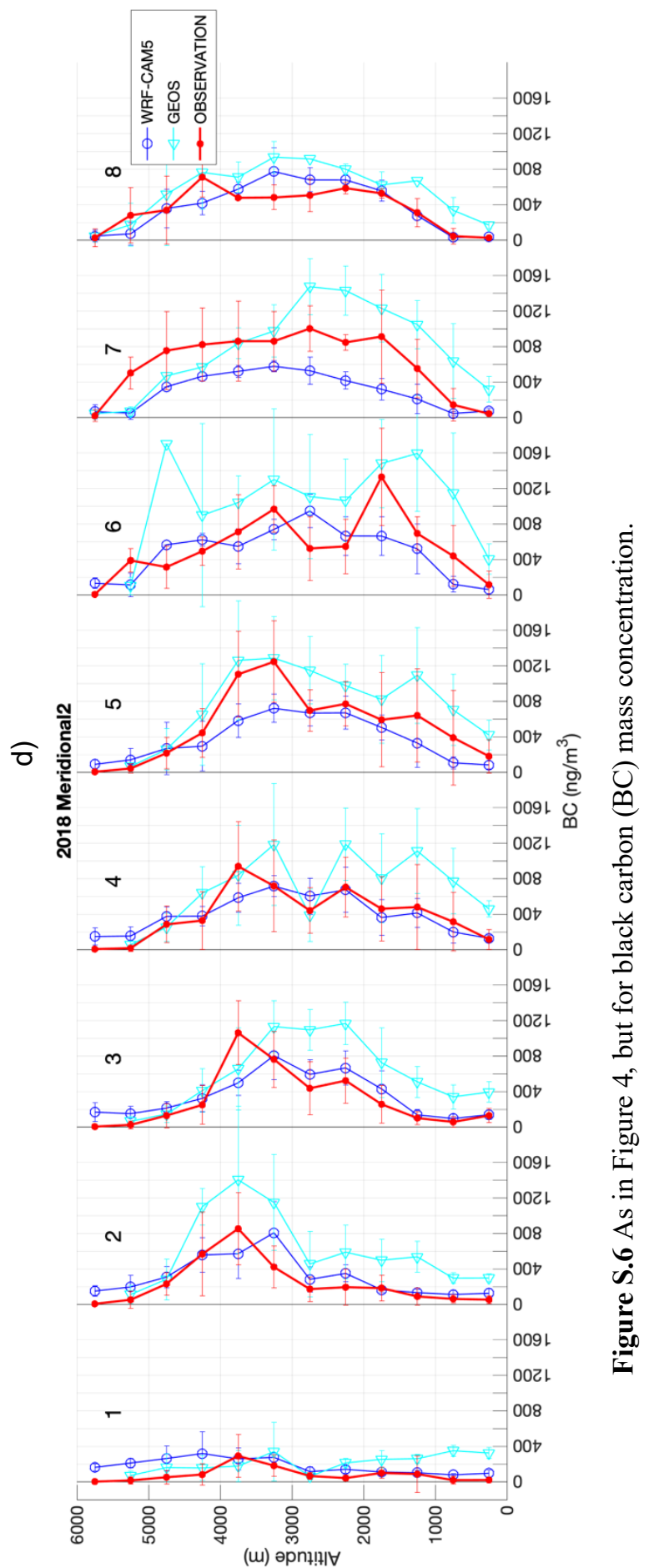


275

280

285

290

295

300

305
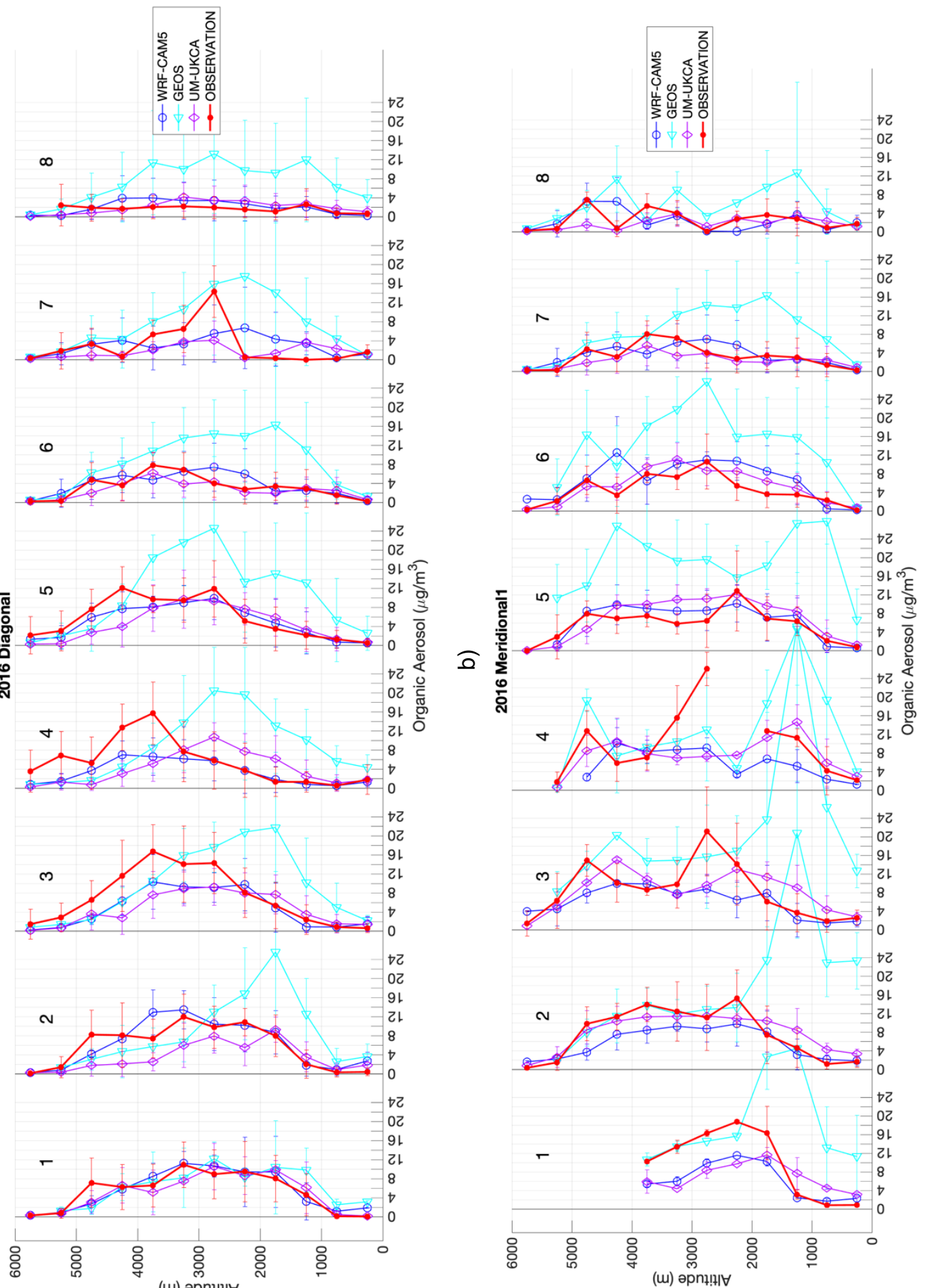
310

315

320

325

330

335

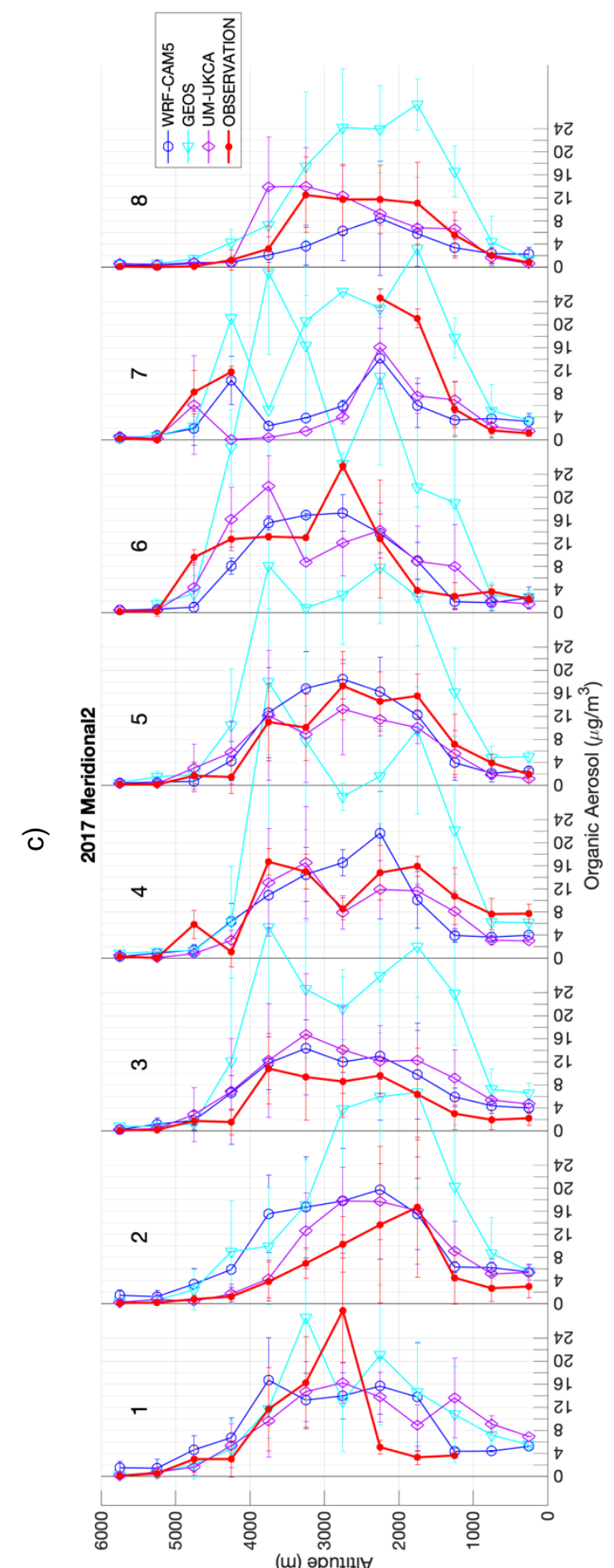

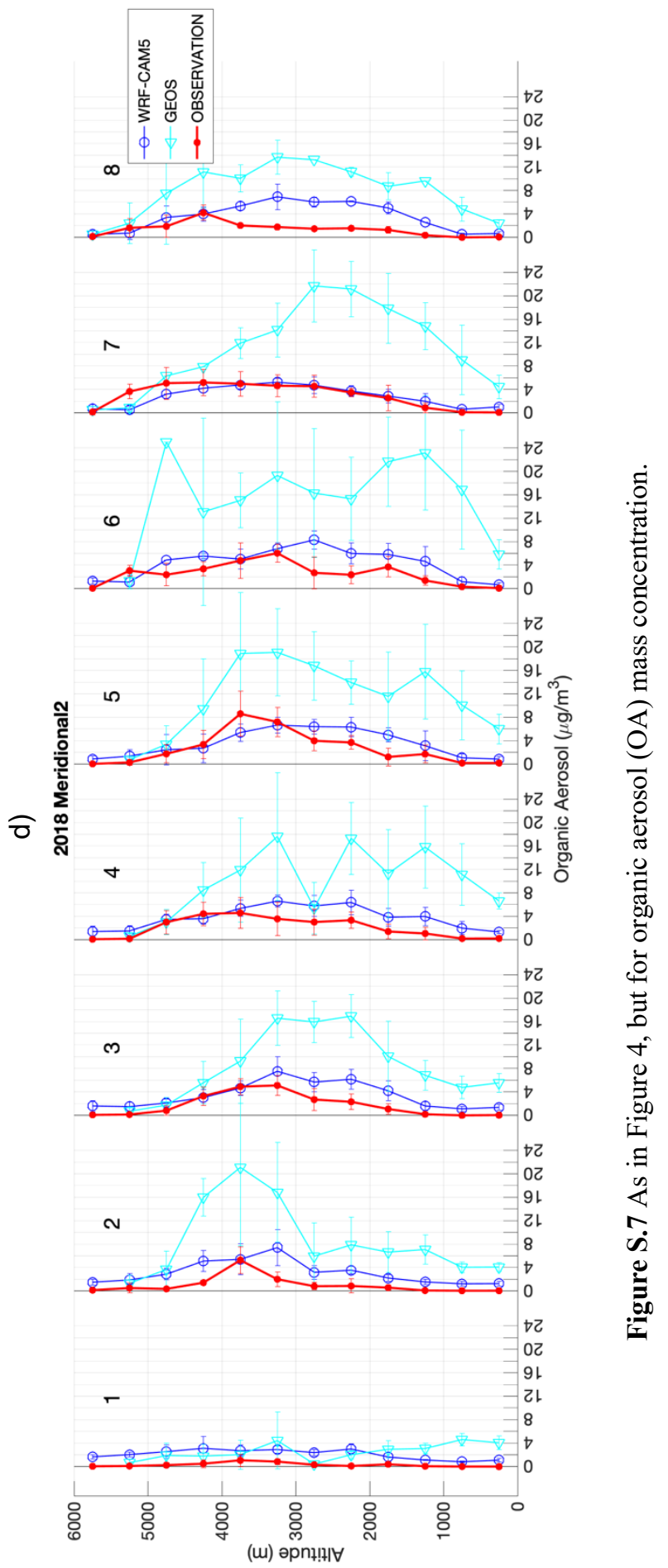



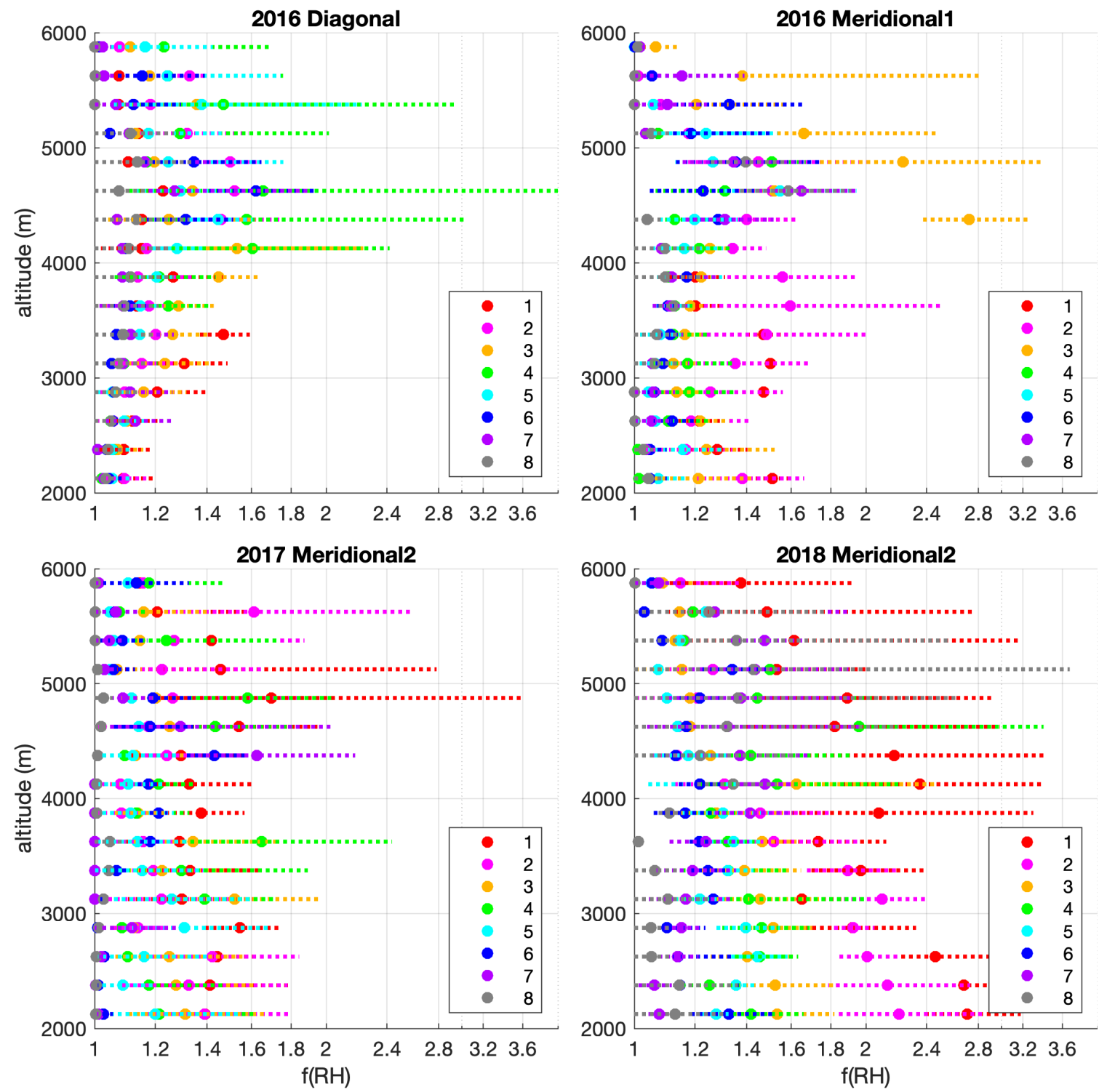

Figure S.8 Light scattering $\left(\sigma_{\mathrm{sp}}\right)$ humidification factor, $\mathrm{f}(\mathrm{RH})$, estimated for adjusting from the measured in-situ at low RH to ambient RH. This estimate uses the gamma fit to low and high (approx. 80\%) RH light scattering measured in-situ in the P-3 aircraft, averaged for all data $2-5 \mathrm{~km}$ altitude where $\sigma_{\mathrm{sp}}>25 \mathrm{Mm}^{-1}$. The campaign-wide averages from $2016(\gamma=0.62)$ and $2018(\gamma=0.62$; used for both 2017 and 2018) are used with observed ambient RH (Figure 6) to calculate the $f(R H)$ values shown here. Solid dots are $f(R H)$ for the gridbox-mean ambient $\mathrm{RH}$ and the dashed horizontal bars for $+/-1$ sigma in ambient $\mathrm{RH}$, with $\mathrm{f}(\mathrm{RH})$ truncated at 1.0 in the lower limit. Colors indicate the gridbox number, as shown in Figure 1. 


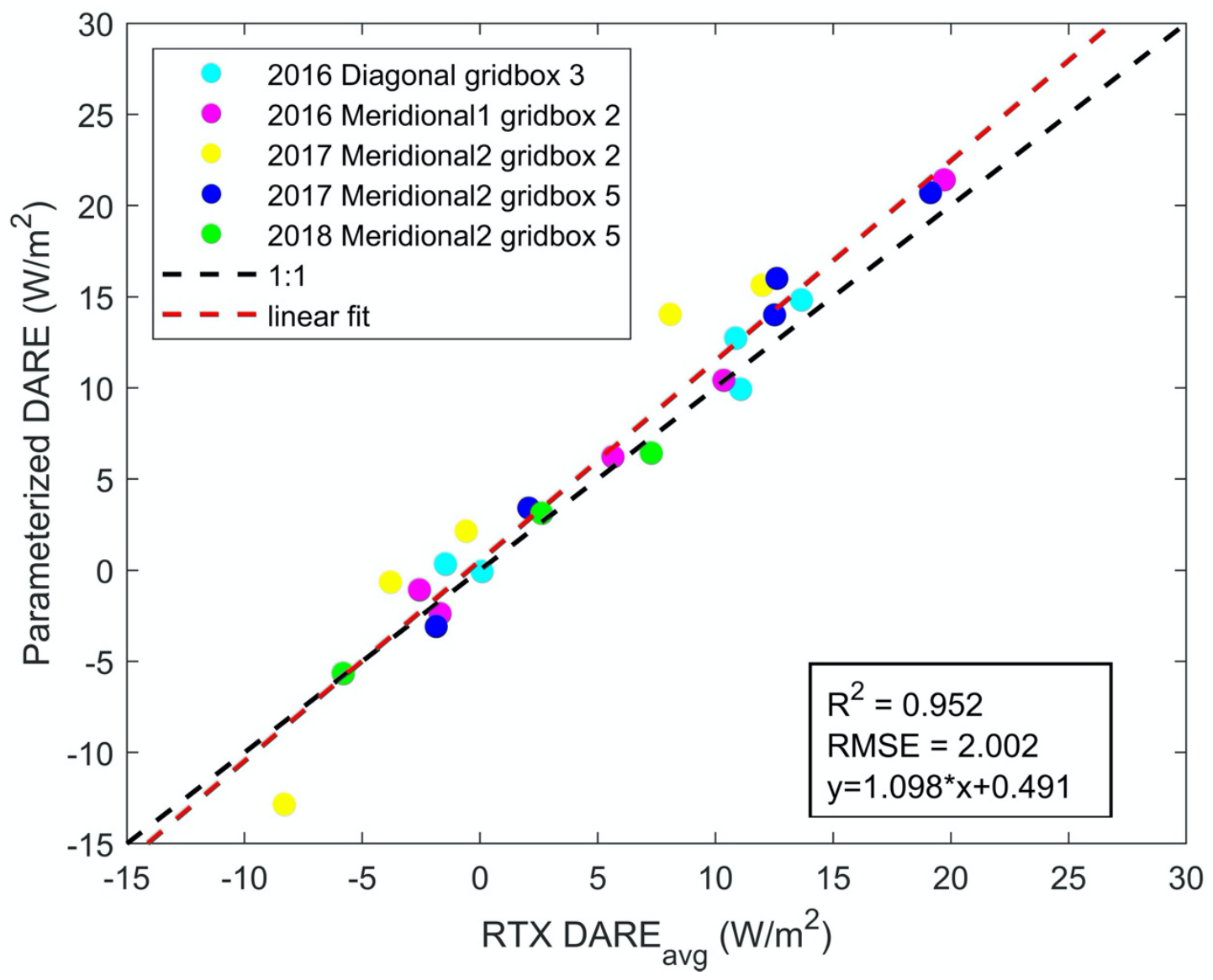

Figure S.9 Comparison of parameterized DARE from Equation [3] versus DARE from full radiative transfer calculations, as described in the text. 